\title{
Effect of Current Velocity on Cd Accumulation in the Aquatic Moss Fontinalis antipyretica
}

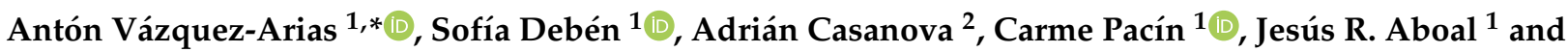 \\ José A. Fernández ${ }^{1}$ (iD) \\ 1 Cretus Institute, Ecology Unit, Biology Faculty, University of Santiago de Compostela, \\ Lope Gómez de Marzoa s/n, Santiago de Compostela, 15702 A Coruña, Spain; debensofia@gmail.com (S.D.); \\ mariadocarme.pacin@rai.usc.es (C.P.); jesusramon.aboal@usc.es (J.R.A.); jangel.fernandez@usc.es (J.A.F.) \\ 2 Department of Zoology, Genetics and Physical Anthropology, Faculty of Veterinary, University of Santiago de \\ Compostela, Avenida Carballo Calero s/n, 27002 Lugo, Spain; adrian.casanova@usc.es \\ * Correspondence: antonvazquez.arias@usc.es or anton.vazquez.arias@gmail.com
}

check for updates

Citation: Vázquez-Arias, A.; Debén, S.; Casanova, A.; Pacín, C.; Aboal, J.R.; Fernández, J.A. Effect of Current Velocity on Cd Accumulation in the Aquatic Moss Fontinalis antipyretica. Water 2021, 13, 157. https://doi.org/ 10.3390/w13020157

Received: 22 December 2020 Accepted: 9 January 2021 Published: 12 January 2021

Publisher's Note: MDPI stays neutral with regard to jurisdictional clai$\mathrm{ms}$ in published maps and institutional affiliations.

Copyright: (C) 2021 by the authors. Licensee MDPI, Basel, Switzerland. This article is an open access article distributed under the terms and conditions of the Creative Commons Attribution (CC BY) license (https:// creativecommons.org/licenses/by/ $4.0 /)$.

\begin{abstract}
With the aim of further standardizing biomonitoring techniques with aquatic mosses, the relationship between the velocity of water flow and cadmium $(\mathrm{Cd})$ accumulation in transplants of the moss Fontinalis antipyretica was investigated. For this purpose, moss transplants were exposed in a controlled aquatic environment to different concentrations of $\mathrm{Cd}\left(0,4,16\right.$ and $\left.36 \mathrm{ng} \mathrm{g}^{-1}\right)$ and different water velocities $\left(10,30,50,70\right.$ and $\left.90 \mathrm{~cm} \mathrm{~s}^{-1}\right)$. The $\mathrm{Cd}$ concentrations in the moss transplants mainly depended on the $\mathrm{Cd}$ concentration in the water, but a small fraction of the variance was explained by water velocity. The $\mathrm{Cd}$ concentrations in moss were standardized to remove the effect of the concentration in the water so all the data could be analyzed together. The regression model for the standardized concentrations explained $23 \%$ of the variance in $\mathrm{Cd}$ accumulation in F. antipyretica and water velocity proved to be a significant predictor of $\mathrm{Cd}$ accumulation.
\end{abstract}

Keywords: biomonitoring; pollution; river; bryophytes; cadmium; water velocity

\section{Introduction}

The pollution of inland water bodies by human activities exacerbates the difficulties experienced by many human populations in accessing safe drinking water, a problem that affects a third of the world's population [1]. This has led to the emergence of laws and acts with the aim of regulating pollution [2,3], which establish maximum allowable concentrations of pollutants in freshwater. Biomonitoring techniques have proven to be useful tools to control these concentrations and they provide advantages over directly analyzing them in the water [4,5].

Various organisms have been used for freshwater biomonitoring, including algae, fish, macroinvertebrate and mosses. Aquatic mosses offer a series of advantages over other organisms: they are immobile, resistant to pollution and have long life cycles [6]. These factors make aquatic mosses good candidates as biomonitoring agents. However, for an organism to be useful for biomonitoring pollutants, the concentrations of pollutants in the tissues must be correlated with the concentrations in the water [3,7]. Unfortunately, reports of such correlations are scarce. Although in recent years an important effort has been made towards standardizing biomonitoring techniques with aquatic mosses (see e.g., [6,8]), other environmental factors that affect the relationship between the pollutant levels in the biomonitors and the water cannot be standardized. These factors include physicochemical parameters of the water, such as $\mathrm{pH}$, temperature, dissolved organic matter, conductivity and velocity $[9,10]$. These factors affect the uptake of pollutants by aquatic mosses, in both passive (collecting organisms living in the water body objective to the study) and active biomonitoring (collecting pieces of moss material, i.e., moss "transplants", from unpolluted sites and exposing them in the study site, in the "moss bag technique"). 
In this study, we attempted to address one of these knowledge gaps: the relationship between the accumulation of pollutants in the moss and the velocity of water in which the moss is immersed. The value of aquatic mosses as biomonitors would be limited if these factors were dependent on each other because it would blur the relationship between the concentrations of elements in water and moss. Increased concentrations of heavy metals in mosses with increasing water velocity could be explained by the following: (a) thinning of the diffusive boundary layer (DBL); (b) an increase in the number of particles carried by the current; and (c) an increase in pollutant flux through the mosses. The DBL is the layer of water in a current next to a surface where, because of the friction with the solid, the flow slows to the point where the main way for elements to go through it is by diffusion [11]. Thus, Croisetière et al. [10] hypothesized that at higher velocities this layer will become thinner, making it easier for pollutants to reach the surface of the moss. However, Gonçalves et al. [12] hypothesized that the increased number of particles carried by rapid flowing waters implies that a greater amount of particles will be retained on the surface of the moss tissues, thus enhancing accumulation of elements. The third possibility is based on the idea that mosses may behave as passive samplers, whereby higher water flow across the moss will lead to a higher pollutant concentration. In this hypothesis it is considered that mosses act as pollutant integrators, i.e., that they take up pollutants cumulatively, as a function of the water concentration, without ever releasing them to the water once accumulated. Nevertheless, it is also possible that the concentrations of elements will tend to reach an equilibrium that will depend on the environmental concentrations (as proposed for terrestrial mosses [13]). In this case, the current velocity would affect the time to reach the equilibrium, but not the final concentration.

To date, the effect of water velocity on pollutant concentrations in aquatic mosses has scarcely been considered. As far as we are aware, only the aforementioned study by Croisetière et al. [10] has analyzed the effect of the current velocity on element accumulation considering every other factor involved. These researchers determined $\mathrm{Cd}$ concentration in the moss Fontinalis dalecarlica exposed to different current velocities and did not find any significant correlation between the flow velocity and $\mathrm{Cd}$ concentrations in the moss. Although the study was well designed, some of the conclusions cannot be applied to field conditions, because the scale of the study was much smaller than most natural water courses (the scale of physical phenomena partly determines the conclusion obtained) and the moss samples were exposed in a different way than is usually done in biomonitoring studies (moss bags). The study findings were unexpected in relation to the findings of previous studies on metal accumulation in Fontinalis antipyretica, which cite current velocity as a possible factor affecting metal capture by the moss [12,14].

The objective of the present study was to examine the relationship between element accumulation in an aquatic moss and water flow velocity. With this aim, we exposed devitalized samples of the moss F. antipyretica to different concentrations of $\mathrm{Cd}$ in the water in a channel of dimensions comparable to those of a natural stream and determined the concentrations accumulated in the moss samples. We selected the species because the same genus was used in previous studies $[10,14]$ and because the species has been recommended for general use as it is the most commonly used in biomonitoring studies. We chose to study $\mathrm{Cd}$ accumulation because $\mathrm{Cd}$ is one of the heavy metals most commonly analyzed in biomonitoring studies $[6,8]$.

\section{Materials and Methods}

\subsection{Obtaining the Moss Samples and Preparing the Transplants}

Shoots of Fontinalis antipyretica Hedw. were collected from an unpolluted stream (approximate center, UTM: 29T 530461 E 4740421 N) in Galicia (NW Spain). The moss samples were rinsed in the stream water and transported to the laboratory in a portable refrigerator. They were then rinsed again with tap water $(5 \mathrm{~L}$ per $150 \mathrm{~g}$ f.w. of moss, for $1 \mathrm{~min}$, with shaking), before the study material was selected. Only the apical section of healthy shoots was used and the basal part, plants in poor condition, epiphytes and 
any other particles were discarded. The moss was devitalized by oven-drying with a temperature ramp $\left(50{ }^{\circ} \mathrm{C}\right.$ for $5 \mathrm{~h}, 80^{\circ} \mathrm{C}$ for $5 \mathrm{~h}$ and $100{ }^{\circ} \mathrm{C}$ for $10 \mathrm{~h}$ ) [15]. The selected, devitalized moss shoots were placed inside flat fiberglass mesh bags $(10 \times 5 \mathrm{~cm} ; 2 \mathrm{~mm}$ aperture; $175 \mathrm{~g}$ of moss per bag), previously washed with $\mathrm{HNO}_{3}$ to eliminate possible Cd contamination.

\subsection{Experimental Setup and Exposure}

For exposure of the moss transplants in a controlled environment, a 3-m-long glass channel of section $21.5 \times 14 \mathrm{~cm}$ was set up in a closed building, as shown in Figure 1. Each end of the channel was connected to a water tank, one of which was positioned slightly higher than the other. The system was fed with $1500 \mathrm{~L}$ of water, which was previously passed through an active carbon filter to remove any particles and trace elements. The water flowed from the higher tank to the lower tank and it was then pumped back to the first tank. The water velocity was measured with a flow meter (Flowmatch, JDC Electronics SA, Yverdon-les-Bains, Switzerland) and was altered by opening or closing a gate at the end of the channel, varying the slope by raising or lowering an attached hydraulic jack and/or varying the power of the pump. Dissolved $\mathrm{Cd}$ was then added to yield nominal concentrations of 5, 20 and $50 \mathrm{ng} \mathrm{g}^{-1}$. A control treatment was also established, without any $\mathrm{Cd}$ added. Stabilization of the concentration of $\mathrm{Cd}$ proved difficult, as the concentration decreased after the $\mathrm{Cd}$ was added. One possible explanation for this is that the metal was absorbed by the fiberglass sides of the tanks, or by other plastic or rubber components of the circuit.

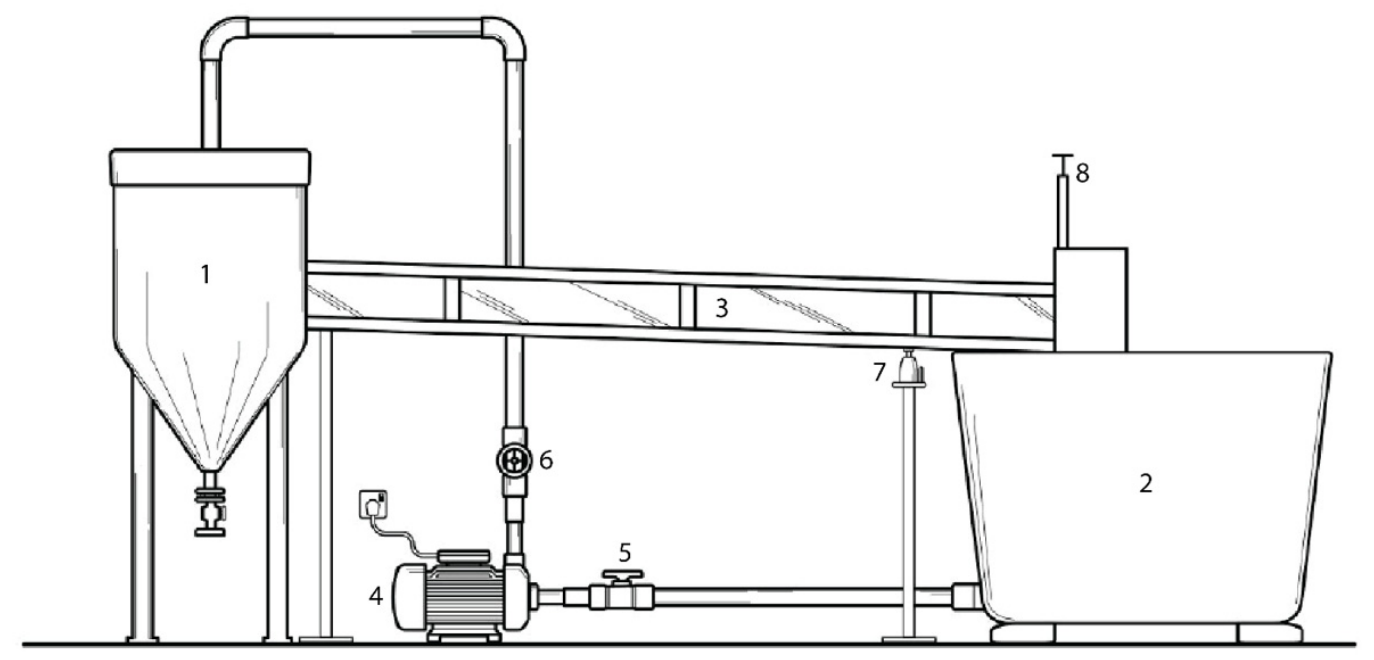

Figure 1. Experimental setup consisting of two water tanks (1 and 2), a glass channel in which the transplants were exposed, covered with a glass lid (3), water pump (4), main valve (5), water flow regulator valve (6), hydraulic jack (7) and a gate (8).

To determine the mean $\mathrm{Cd}$ concentrations in the water during each experiment, two samples of the water were collected every day during each of the exposure periods and also immediately before and after each exposure period. The actual mean concentrations of $\mathrm{Cd}$ in the water were 4,16 and $36 \mathrm{ng} \mathrm{g}^{-1}$. After each exposure period, the concentration was corrected by adding more $\mathrm{Cd}$.

For each Cd concentration, including the control $\left(0 \mathrm{ng} \mathrm{g}^{-1} \mathrm{Cd}\right)$, the experiment was run at 5 different water flow velocities: 10,30, 50,70 and $90 \mathrm{~cm} \mathrm{~s}^{-1}$. These values were selected to cover the usual range of current velocities in natural streams, roughly up to $1.5 \mathrm{~m} \mathrm{~s}^{-1}$ [16], although stabilizing the flow of the channel faster than $1 \mathrm{~m} \mathrm{~s}^{-1}$ was not possible. The velocity was checked during the experiment and was found to remain constant. For all combinations of dissolved Cd and current velocity, 3 moss transplants, fastened with ties to prevent contact with any surface, were exposed for 5 days. The experiment lasted approximately 6 months, including each week-long exposure time, plus 
the time to stabilize the $\mathrm{Cd}$ concentrations in the water. After each exposure period, the transplants were collected, oven-dried at $40^{\circ} \mathrm{C}$, homogenized in an ultracentrifuge mill (heavy metal-free, ZM200, Retsch, Haan, Germany) and stored in glass vials in darkness at room temperature until chemical analysis. In addition, 3 moss bags were used as preexposure controls, i.e., they were not exposed but were otherwise processed in the same way as other bags.

\subsection{Analytical Procedures}

The $\mathrm{Cd}$ concentrations were determined by flame atomic absorption spectrometry (Optima 2100 DV, Perkin Elmer, Waltham, MA, USA). Moss and water samples in which concentrations were below the limit of determination of the former were analyzed by graphite furnace atomic absorption spectrophotometry (AAnalyst 600, Perkin Elmer, Waltham, MA, USA).

The normality of the data was checked with the Shapiro-Wilk test. As almost all of the data were normally distributed, the differences among groups were determined by ANOVA, which can be robust even when the normality assumption does not hold [17]. Linear regression models were used to study the relationship between variables and the model assumptions were checked by visual inspection of the data. To assess the effect of current velocity at all concentrations of $\mathrm{Cd}$ in the water, the concentrations of $\mathrm{Cd}$ in moss were normalized by dividing the values by the mean concentrations in the samples exposed to the same concentration of $\mathrm{Cd}$ in the water. All statistical analyses were performed with R software [18].

\section{Results and Discussion}

The relationship between $\mathrm{Cd}$ concentrations in moss and water flow velocity as a function of the $\mathrm{Cd}$ concentration in the water is shown in Figure 1. Very clear differences between moss transplants exposed to different concentrations of $C d$ in water $(p<0.001)$ were observed. This effect was expected, as this dependence is the reason why aquatic mosses are used as biomonitors, and it has already been clearly demonstrated (see e.g., $[5,19,20])$.

Concentration of $\mathrm{Cd}$ was lowest in the moss transplants exposed to water without any $\mathrm{Cd}$ added $\left(1.23 \mu \mathrm{g} \mathrm{g}^{-1}\right)$ and it was even lower than the mean concentration in the pre-exposure control samples $\left(2.77 \mu \mathrm{g} \mathrm{g}^{-1}\right)$. This can probably be explained by the fact that the $\mathrm{Cd}$ concentrations in the filtered water used for the experiment were lower than in the stream where the moss was collected and therefore the excess Cd was washed out. As all the samples were removed from the experimental system after 5 days, the concentrations were probably very close to equilibrium, as most elements reach an equilibrium after 7 days $[21,22]$. The aforementioned finding supports the idea that aquatic mosses do not act as integrators, simply accumulating metals during the exposure period, but rather that an equilibrium is reached, not unlike what occurs with terrestrial mosses used in atmospheric biomonitoring [13].

The current velocity, on the other hand, appeared to have a much smaller effect. Linear regression models predicting $\mathrm{Cd}$ concentration in the transplants based on current velocity were constructed for each water concentration. However, because of the small sample size (15 data points for each concentration) it was difficult to verify whether the assumptions of linearity, normality and homoscedasticity of residuals were fulfilled. Visual examination of each group suggests approximate compliance with the assumptions (Figure S1). The best fit lines for these models are shown in Figure 2. 


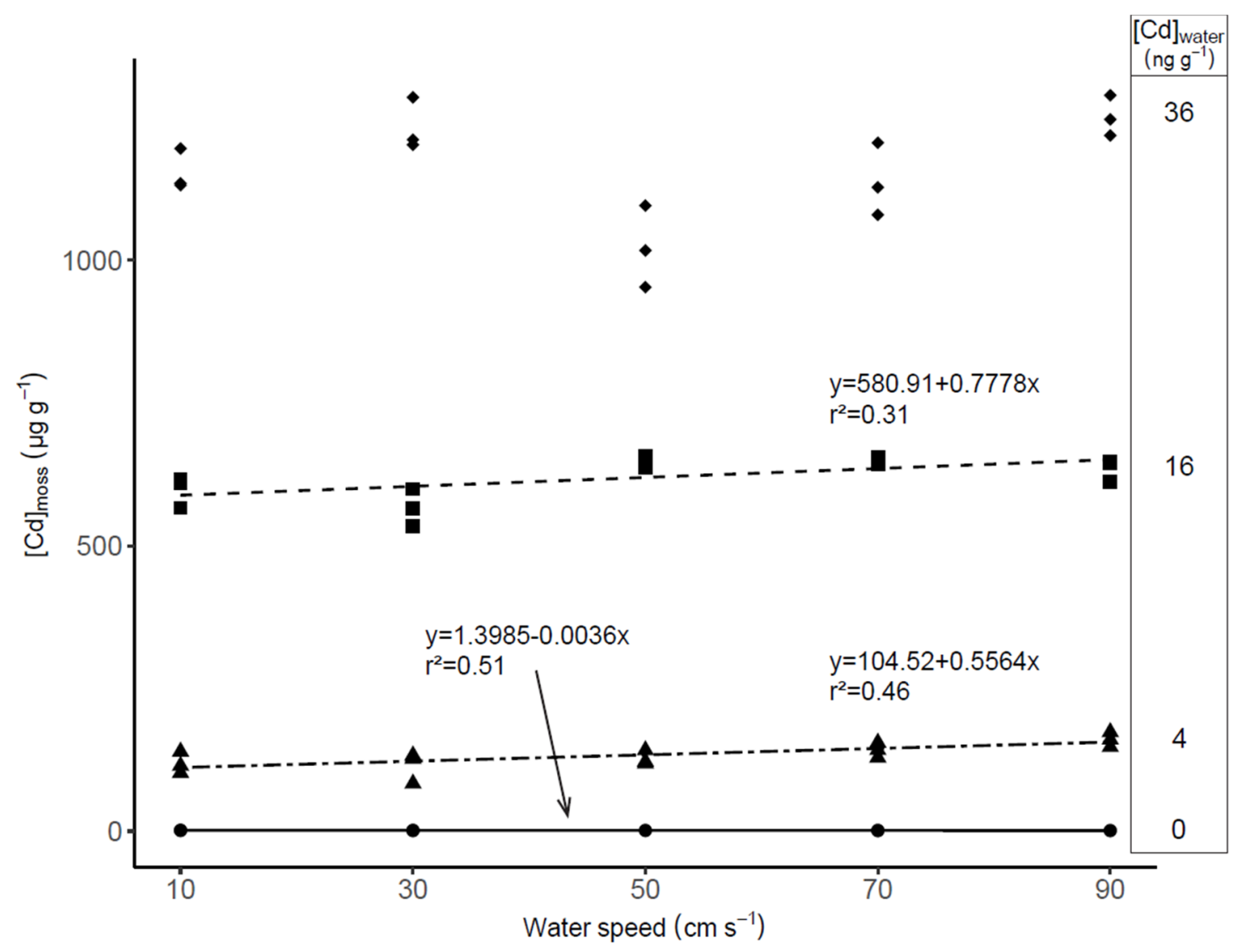

Figure 2. Correlation between the concentration of $\mathrm{Cd}$ in Fontinalis antipyretica transplants and water velocity depending on the concentration of $\mathrm{Cd}$ in the water. The best fit lines of the models for each group exposed to different concentrations are shown for 0,4 and $16 \mathrm{ng} \mathrm{g}^{-1}$ of $\mathrm{Cd}$ in water. For these models, both the intercepts and the slopes are significant $(p<0.05)$. The model was not significant for the samples exposed to $36 \mathrm{ng} \mathrm{g}^{-1}$ of $\mathrm{Cd}$. The formula and the adjusted $\mathrm{r}^{2}$ of each model are shown next to each best fit line. In the control $(0 \mathrm{Cd})$ group, the variance was small, and the points for the 3 replicates overlap in the figure.

The current velocity appeared to have a slight effect on the $\mathrm{Cd}$ concentration in the transplants: in the samples exposed to water without $\mathrm{Cd}$ added, the current velocity and $\mathrm{Cd}$ concentration were negatively related, which is consistent with the idea that release of $\mathrm{Cd}$ from the moss (approaching equilibrium) increases directly with the current velocity. In the transplants exposed to water to which $\mathrm{Cd}$ was added, there seemed to be a positive effect, at least in the samples exposed to 4 and $16 \mathrm{ng} \mathrm{g}^{-1}$ of $\mathrm{Cd}$ in water, for which the model was significant. For the group exposed to $36 \mathrm{ng} \mathrm{g}^{-1}$, the linear regression was not significant, probably due to the variation in the concentration of $\mathrm{Cd}$ in the water in which the transplants were immersed, which was higher than in the other groups.

To overcome the challenge of obtaining significant results with small numbers of samples, the $\mathrm{Cd}$ concentrations in moss were normalized by dividing each value by the mean value obtained for the samples exposed to the same $\mathrm{Cd}$ concentration in water. This allowed us to test our hypothesis by using data from different groups while maintaining the variation in each. The scatter plot and the best fit line for the model constructed with these data are presented in Figure 3. 


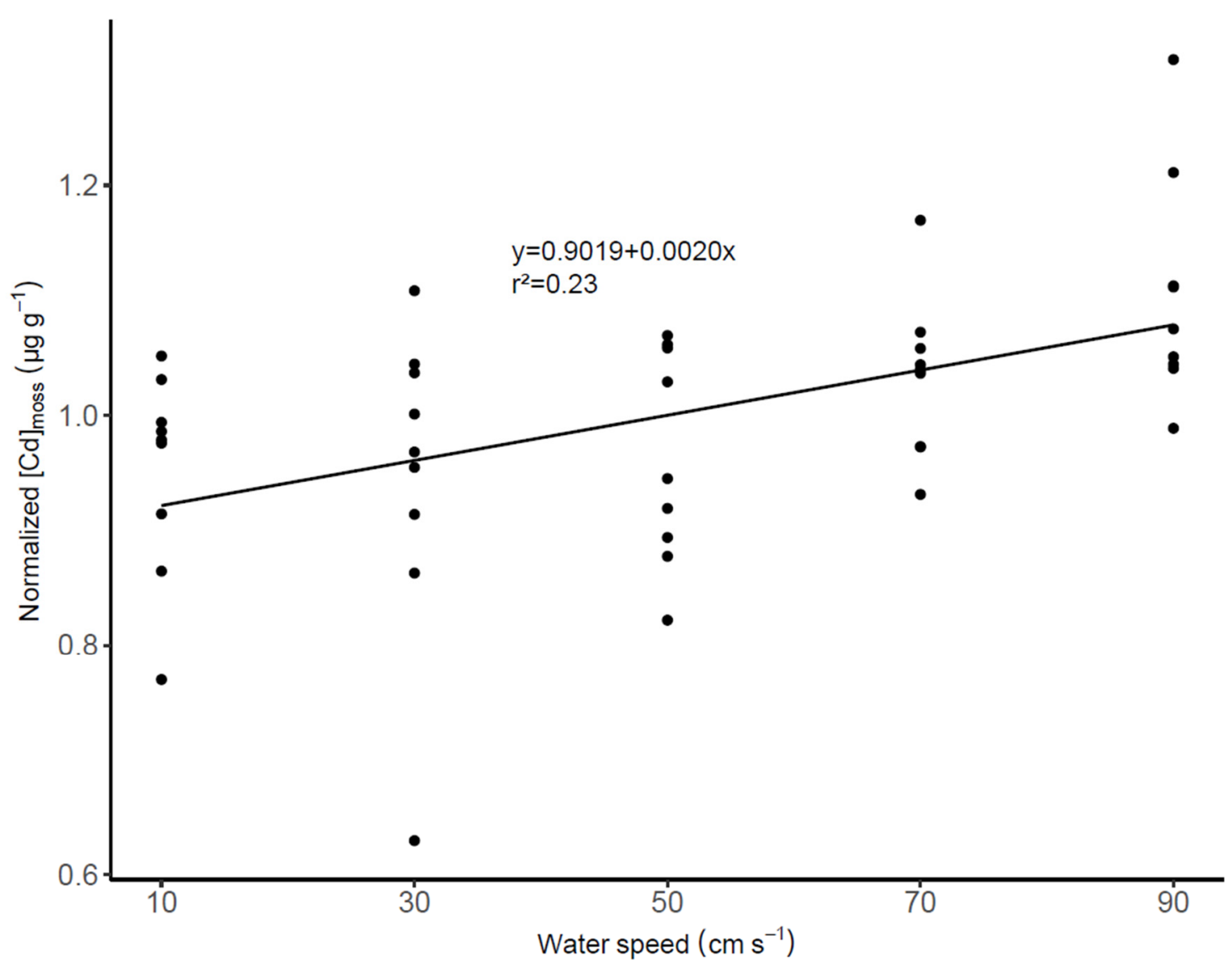

Figure 3. Linear regression of the concentration of $\mathrm{Cd}$ in Fontinalis antipyretica transplants normalized by the Cd concentration in water, depending on water velocity. The formula and the adjusted $\mathrm{r}^{2}$ of the model are shown. The intercept and the slope are significant $(p<0.05)$.

The model explained $23 \%$ of the variance and the regression coefficient was highly significant, clearly indicating that for the range of velocities tested, which cover those in most natural river courses [16], accumulation of Cd by F. antipyretica depends on the flow velocity of the water in which the moss is immersed. This finding contrasts with the results reported by Croisetière et al. [10], who found no relationship between these two factors, but it is consistent with the relationship expected by Gonçalves et al. [12]. Despite the fact that Croisetière et al. [10] found no proof of the dependence of metal accumulation on current velocity, the hypothesis that these authors suggested for explaining the effect seems to be correct, i.e., faster currents making the DBL around the moss surface thinner would cause an increased accumulation of elements. By contrast, the hypothesis proposed by Gonçalves et al. [12] would not explain these results: greater numbers of particles at higher current velocities do not explain the concentrations of $\mathrm{Cd}$ in moss in our experiment, as all the $\mathrm{Cd}$ in our artificial stream was dissolved and there would not be large numbers of particles available to adhere to the moss surface.

The existence of the relationship between the speed of the current and accumulation of pollutants in mosses poses a difficulty for the use of these organisms as aquatic biomonitors, as current must be considered when using this technique to obtain information about the concentrations of pollutants in the water. Otherwise, the variability created by this factor, among others, will blur the correlation between the concentrations in the moss and the water required for biomonitoring [3,7].

\section{Conclusions}

Accumulation of $\mathrm{Cd}$ by devitalized transplants of the moss F. antipyretica is affected by the velocity of the water in which the transplants are immersed. This finding is consistent 
with the hypothesis that mosses act as integrators of pollutants; however, as the moss can release $\mathrm{Cd}$ when exposed to low concentrations, it is more likely that an equilibrium with the concentrations in the water will be reached and be slightly altered by the water velocity. This effect should be taken into account to obtain precise measurements of the concentrations of $\mathrm{Cd}$ in inland water bodies in biomonitoring surveys.

Supplementary Materials: The following are available online at https:/ /www.mdpi.com/2073-4 441/13/2/157/s1, Figure S1: Residuals vs. fitted values and Q-Q plots for the models relating Cd concentration in the moss with water flow velocity.

Author Contributions: Conceptualization, J.R.A. and J.A.F.; methodology, S.D. and A.C.; formal analysis, A.V.-A. and S.D.; investigation, S.D., A.C. and C.P.; writing-original draft preparation, A.V.-A.; writing-review and editing, C.P., J.R.A. and J.A.F.; funding acquisition, J.R.A. and J.A.F. All authors have read and agreed to the published version of the manuscript.

Funding: The study was partly financed by the Spanish Government (project CTM2016-70578-P).

Institutional Review Board Statement: Not applicable.

Informed Consent Statement: Not applicable.

Data Availability Statement: The data presented in this study are available within this article (Figure 2). More precise data are available on request from the corresponding author.

Acknowledgments: A. Vázquez-Arias is grateful to the Spanish Ministerio de Ciencia, Innovación y Universidades for a grant awarded within the Programa de Formación de Profesorado Universitario (FPU 2020). The authors are grateful to Pablo Amosa for designing and elaborating Figure 1.

Conflicts of Interest: The authors declare no conflict of interest.

\section{References}

1. Schwarzenbach, R.P.; Egli, T.; Hofstetter, T.B.; Von Gunten, U.; Wehrli, B. Global Water Pollution and Human Health. Annu. Rev. Environ. Resour. 2010, 35, 109-136. [CrossRef]

2. European Commission. European Parliament and of the Council Common Implementation Strategy for the Water Framezork Directive (2000/60/EC): Guidance Document No. 25. Guidance on Chemical Monitoring of Sediments and Biota under Water Framework Directive; Office for the Official Publications in the European Communities: Luxembourg, 2010.

3. US EPA. Clean Water Act; US EPA: Washington, DC, USA, 1972.

4. Burton, M.A.S.; Peterson, P.J. Metal accumulation by aquatic bryophytes from polluted mine streams. Environ. Pollut. 1979, 19, 39-46. [CrossRef]

5. Say, P.J.; Harding, J.P.C.; Whitton, B.A. Aquatic mosses as monitors of heavy metal contamination in the river etherow, great britain. Environ. Pollut. Ser. B Chem. Phys. 1981, 2, 295-307. [CrossRef]

6. Debén, S.; Aboal, J.R.; Carballeira, A.; Cesa, M.; Fernández, J.A. Monitoring river water quality with transplanted bryophytes: A methodological review. Ecol. Indic. 2017, 81, 461-470. [CrossRef]

7. Phillips, D.J.H. Quantitative Aquatic Biological Indicators: Their Use to Monitor Trace Metal and Organochlorine Pollution; Applied Science Publishers: Barking, UK, 1980.

8. Debén, S.; Aboal, J.R.; Carballeira, A.; Cesa, M.; Real, C.; Fernández, J.A. Inland water quality monitoring with native bryophytes: A methodological review. Ecol. Indic. 2015, 53, 115-124. [CrossRef]

9. Vázquez, M.D.; López, J.; Díaz, S.; Carballeira, A. The effect of pH on the kinetics of intra- and extracellular uptake of Al in Fontinalis antipyretica: Changes in the cellular contents of $\mathrm{K}, \mathrm{Mg}$, and Ca. Arch. Environ. Contam. Toxicol. 2000, 39, 74-85. [CrossRef] [PubMed]

10. Croisetière, L.; Hare, L.; Tessier, A. Influence of Current Velocity on Cadmium Accumulation by an Aquatic Moss and the Consequences for Its Use as a Biomonitor. Environ. Sci. Technol. 2001, 35, 923-927. [CrossRef] [PubMed]

11. Jørgensen, B.B.; Des Marais, D.J. The diffusive boundary layer of sediments: Oxygen microgradients over a microbial mat. Limnol. Oceanogr. 1990, 35, 1343-1355. [CrossRef] [PubMed]

12. Gonçalves, E.P.R.; Boaventura, R.A.R.; Mouvet, C. Sediments and aquatic mosses as pollution indicators for heavy metals in the Ave river basin (Portugal). Sci. Total Environ. 1992, 114, 7-24. [CrossRef]

13. Aboal, J.R.; Fernández, J.A.; Boquete, T.; Carballeira, A. Is it possible to estimate atmospheric deposition of heavy metals by analysis of terrestrial mosses? Sci. Total Environ. 2010, 408, 6291-6297. [CrossRef] [PubMed]

14. Say, P.J.; Whitton, B.A. Accumulation of heavy metals by aquatic mosses. 1: Fontinalis antipyretica Hedw. Hydrobiologia 1983, 100, 245-260. [CrossRef]

15. Debén, S.; Fernández, J.A.; Carballeira, A.; Aboal, J.R. Using devitalized moss for active biomonitoring of water pollution. Environ. Pollut. 2016, 210, 315-322. [CrossRef] 
16. Schulze, K.; Hunger, M.; Döll, P. Simulating river flow velocity on global scale. Adv. Geosci. 2005, 5, 133-136. [CrossRef]

17. Zar, J.H. Biostatistical Analysis, 5th ed.; Prentice-Hall: Upper Saddle River, NJ, USA, 2010.

18. R Core Team. R: A Language and Environment for Statistical Computing; R Core Team: Vienna, Austria, 2020.

19. Favas, P.J.C.; Pratas, J.; Rodrigues, N.; D'Souza, R.; Varun, M.; Paul, M.S. Metal(loid) accumulation in aquatic plants of a mining area: Potential for water quality biomonitoring and biogeochemical prospecting. Chemosphere 2018, 194, 158-170. [CrossRef] [PubMed]

20. García-Álvaro, M.A.; Martínez-Abaigar, J.; Núñez-Olivera, E.; Beaucourt, N. Element concentrations and enrichment ratios in the aquatic moss Rhynchostegium riparioides along the River Iregua (La Rioja, northern Spain). Bryologist 2000, 103, 518-533. [CrossRef]

21. López, J.; Vázquez, M.D.; Carballeira, A. Stress responses and metal exchange kinetics following transplant of the aquatic moss Fontinalis antipyretica. Freshw. Biol. 1994, 32, 185-198. [CrossRef]

22. Fernández, J.A.; Vázquez, M.D.; López, J.; Carballeira, A. Modelling the extra and intracellular uptake and discharge of heavy metals in Fontinalis antipyretica transplanted along a heavy metal and $\mathrm{pH}$ contamination gradient. Environ. Pollut. 2006, 139, 21-31. [CrossRef] [PubMed] 